Article

\title{
Large Eddy Simulation of Film Cooling Involving Compound Angle Hole with Bulk Flow Pulsation
}

\author{
Seung-Il Baek (1) and Joon Ahn *(1) \\ School of Mechanical Engineering, Kookmin University, 77 Jeongneung-ro, Seongbuk-gu, Seoul 02707, Korea; \\ greenjet50@gmail.com \\ * Correspondence: jahn@kookmin.ac.kr
}

check for updates

Citation: Baek, S.-I.; Ahn, J. Large Eddy Simulation of Film Cooling Involving Compound Angle Hole with Bulk Flow Pulsation. Energies 2021, 14, 7659. https://doi.org/ 10.3390/en14227659

Academic Editors: Tong Seop Kim, Jae Su Kwak and George Kosmadakis

Received: 19 October 2021

Accepted: 15 November 2021

Published: 16 November 2021

Publisher's Note: MDPI stays neutral with regard to jurisdictional claims in published maps and institutional affiliations.

Copyright: (c) 2021 by the authors. Licensee MDPI, Basel, Switzerland. This article is an open access article distributed under the terms and conditions of the Creative Commons Attribution (CC BY) license (https:// creativecommons.org/licenses/by/ $4.0 /)$.

\begin{abstract}
The effects of pulsations in the main flow on film cooling from a cylindrical hole with a spanwise injection angle (orientation angle) are analyzed using numerical methods. The hole is located on a flat plate with a $35^{\circ}$ inclined injection angle, and the compound angle denotes the orientation and inclination angles. The film cooling flow fields for the sinusoidal flow pulsation of $36 \mathrm{~Hz}$ from a cylindrical hole with $0^{\circ}$ and $30^{\circ}$ orientation angles at the time-averaged blowing ratio of $M=0.5$ are simulated via large eddy simulation (LES). The CFD results are validated using the experimental data and compared to the Reynolds-averaged Navier-Stokes (RANS) and URANS results. The results reveal that if the pulsation frequency goes from 0 to $36 \mathrm{~Hz}$, the adiabatic film cooling effectiveness decreases regardless of the compound angle; however, the film cooling for the $30^{\circ}$ orientation angle exhibits better performance than that for a simple angle $\left(0^{\circ}\right)$. Moreover, if $36 \mathrm{~Hz}$ pulsation is applied, the film cooling effectiveness obtained by unsteady RANS exhibits a large deviation from the experimental data, unlike the LES results. The credibility of the LES results relative to the experimental data is demonstrated by comparing the time-averaged $\eta$ and the phase-averaged temperature contours. The LES results demonstrate that LES can more accurately predict $\eta$ than the experimental data; in contrast, URANS results are highly overpredicted around the centerline of the coolant spreading. Thus, LES results are more consistent with the experimental results for the time- and phase-averaged temperature contours than the URANS results.
\end{abstract}

Keywords: large eddy simulation; Reynolds-averaged Navier-Stokes simulation; gas turbine cooling; film cooling

\section{Introduction}

The Brayton cycle demonstrates that gas turbine efficiency can be increased by increasing the inlet temperature [1]. The temperature of the blade surface should be kept below the acceptable limit to prevent excessive thermal stress. The cooling air is injected through small holes on the blade surface, and it protects the wall from hot main flow by reducing the wall temperature. The investigation of the film cooling performance using numerical methods such as Reynolds-averaged Navier-Stokes simulation (RANS), large eddy simulation (LES), or detached eddy simulation (DES) costs less than experiments. The LES predicts the mixing between the cross flow and injectant better than the RANS approach, even though its computation time is significantly longer [2-4]. Numerous CFD studies have attempted to understand the film cooling physics when the cross flow is steady.

In a numerical study under the steady state, Walters and Leylek (2000) employed the standard $k-\varepsilon$ model for a three-dimensional (3-D) unstructured mesh to simulate film cooling on a flat plate [5]. They determined that the model did not well predict the reattachment of the coolant in the narrow field at high blowing ratios. Moreover, they 
stated that the RANS results overpredicted $\eta_{c}$ and displayed less lateral coolant spreading on the wall. The effectiveness, $\eta$, is defined in Equation (1).

$$
\eta=\frac{\left(T_{G}-T_{a w}\right)}{T_{G}-T_{C}}
$$

where $T_{a w}$ is the adiabatic wall temperature, $T_{G}$ represents the main flow temperature, and $T_{C}$ is the coolant temperature. Furthermore, Tyagi and Acharya (2003) conducted LES for film cooling simulations [6]. They employed a dynamic mixed model and applied the velocity profiles obtained by RANS to the hole inlet. They stated that the LES better predicted $\eta$ than RANS; this is since LES can predict the coherent structures of the film cooling. Rozati and Tafti (2007) studied the influence of the freestream turbulence on film cooling using LES [7]. They found the counter rotating vortex pair (CRVP) and showed that the fully turbulent jet decreased $\eta$ by increasing the mixing with the cross flow. Na et al. (2007) demonstrated that a ramp installed upstream of the hole can increase $\eta$ since the ramp results in the interaction between the cross flow and injectant being further away from the test plate, causing the formation of a weak horseshoe vortex [8]. In their simulations, they employed the realizable $k-\varepsilon$ model. Johnson et al. (2011) showed the effects of the hole length to hole diameter ratio, momentum ratio on $\eta$ using the realizable $k-\varepsilon$ model [9]. They determined that the mesh refinement around the hole trailing edge was helpful for yielding better $\eta$ at high momentum ratios. Moreover, they stated that $\eta$ was low when the injectant had high momentum, and the ratio of $L / D$ was small due to the high injectant lift off. The various CFD studies on film cooling show that LES simulation is superior to RANS simulation for predicting the film cooling performance at $0 \mathrm{~Hz}$. Additionally, the cooling jet can be injected from the hole with a spanwise injection angle to the main flow. When a compound angle is implemented, the film cooling performance improves as the CRVP changes to a single vortex $[10,11]$. Lee et al. studied the film cooling flow variation with $\beta$ ranging from $15^{\circ}$ to $90^{\circ}$ experimentally [12]. They discovered that the CRVP of the injectant exhibits a strong asymmetry at an orientation angle of $15^{\circ}$ and changes to a single vortex at an orientation angle of $30^{\circ}$. Jung and Lee [13] experimentally measured $\eta$ variation with the compound angle. When a compound angle was adopted, $\eta$ increased from $20 \%$ to $80 \%$ depending on the orientation angle and blowing ratio.

However, unsteady main flow could be generated in the film cooling flow fields because of several reasons, such as flow interactions between the stator and rotor [14]. Thus, understanding the effects of the pulsating main flow on the film cooling performance is important for high efficiency design of the gas turbine. However, little experimental research and few numerical studies have been conducted on the effects of pulsating main flow on film cooling. Coulthard et al. (2000) showed the effects of cooling air pulsation on the film cooling performance experimentally [15]. They found that $\eta$ decreased when the frequency of the pulsation of the coolant injection increased. Moreover, they found that the best cooling performance was obtained at an $M$ of 0.5 . Nikitopoulos and Acharya (2009) showed the effect of the injectant pulsation on film cooling and found that $\eta$ can be controlled and improved by the injectant pulsation numerically [16]. They stated that frequency, duty cycle, and $M$ affect the film cooling performance. The instability pattern can be approximated by a sinusoidal form, since the instability pattern is more similar to a sinusoidal waveform than a simple pulse. Seo et al. (1998) experimentally showed the effects of sinusoidal pulsations of 2,16 , and $32 \mathrm{~Hz}$ on film cooling [14]. They reported that when the frequencies were increased at $M=0.5$ and short $L / D, \eta$ was decreased and the heat transfer coefficients was increased. Jung et al. (2001) experimentally investigated the effects of sinusoidal pulsations in the mainstream on film cooling [17]. They reported the flow structures of the film cooling via phase- and time-averaged velocity profiles, with Reynolds stresses at $0,2,16$, and $32 \mathrm{~Hz}$ for $M=0.5$. Moreover, they showed that the influence on the flow structures increased with the pulsation frequencies. Generally, the computational cost of LES is significantly higher than that of RANS. However, RANS has a limitation in the prediction of complex flow structures induced in film cooling flow fields, since all 
turbulent fluctuations are ensemble-averaged, while LES directly resolves eddies of large scale in the flow, yielding accurate, complex flow predictions $[18,19]$.

This study aims to verify whether LES, compared to RANS and URANS, significantly improves the prediction of the film cooling from a cylindrical hole involving a compound angle under unsteady flow condition. Sinusoidal pulsation is applied in the main flow, and the effects of the pulsations on film cooling from a cylindrical hole on a flat wall at time-averaged blowing ratio of 0.5 are investigated using LES. The computational results are validated using the experimental results from Jung [17] and compared to the RANS results.

\section{Numerical Method}

\subsection{Computational Domain and Grid}

Figure 1 schematically illustrates the cylindrical hole configurations with orientation angles $\beta$ of $0^{\circ}$ and $30^{\circ}$. The orientation angle $\beta$ is the angle between the streamwise direction and projected injection vector on the wall. Moreover, the hole is located on a flat plate with a $35^{\circ}$ inclined injection angle. The inclination angle is the angle between the injection and projected injection vectors on the wall. The compound angle represents the orientation and inclination angles. Figure 2 shows the computational fluid dynamic (CFD) domains of the cylindrical holes. The hole system geometry is based on that presented in [17], wherein the experimental equipment comprises a row of five cooling holes. However, herein, to save computational costs, a single hole configuration is adopted, and periodic boundary conditions are used at the centerline between the holes $(z= \pm 1.5 \mathrm{D})$. The diameter of the hole $(D)$, the ratio of $L / D$, the angle of injection $(\alpha)$, and the ratio of the pitch over the hole diameter were $20 \mathrm{~mm}, 4,35^{\circ}$, and 3, respectively. Figure 3 shows the overall view of the 3 -D mesh on the $z=0$ plane, the close-up view of the mesh near the cooling hole, and the view of the mesh on the cross-sectional plane at the hole exit. The real turbine blade has a more complex shape than the domain; however, with some corrections, the flat plate results can be used in real turbine blades [19]. The geometry from Jung et al. (2001) was considered herein [17].

\subsection{Governing Equations and Boundary Conditions}

Newtonian incompressible fluid was used, and the time-averaged blowing ratio was set as $M=0.5$. The mainstream velocity was $10 \mathrm{~m} / \mathrm{s}$. The main flow and injectant velocities were considerably less than Mach 0.3, and the compressibility effect was not considered [20,21]. The governing CFD simulation equations comprised the continuity, momentum, and energy equations.
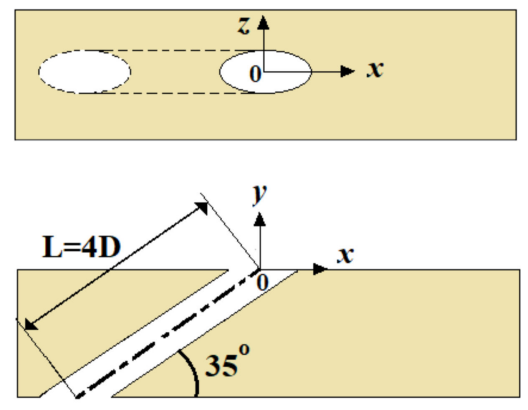

(a)
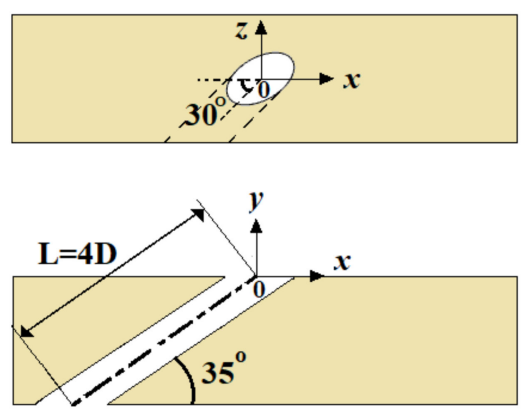

(b)

Figure 1. Details of the cylindrical hole configuration used with orientation angle $\beta$ of $0^{\circ}$ and $30^{\circ}$. (a) $\beta=0^{\circ}$; top: top view, bottom: side view; (b) $\beta=30^{\circ}$; top: top view, bottom: side view. 


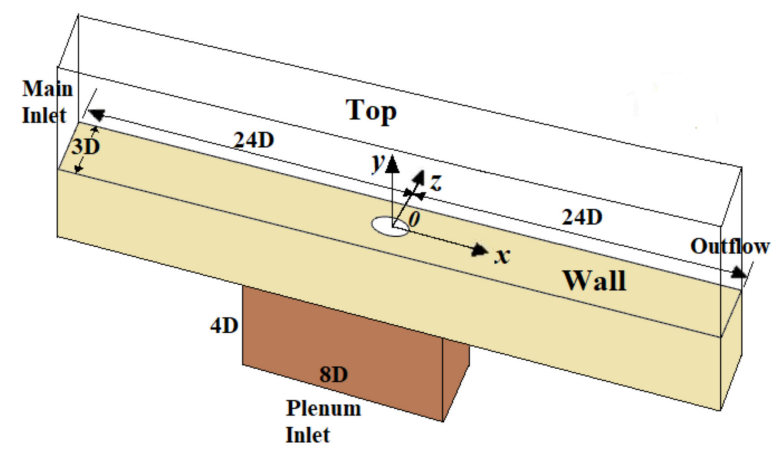

(a)

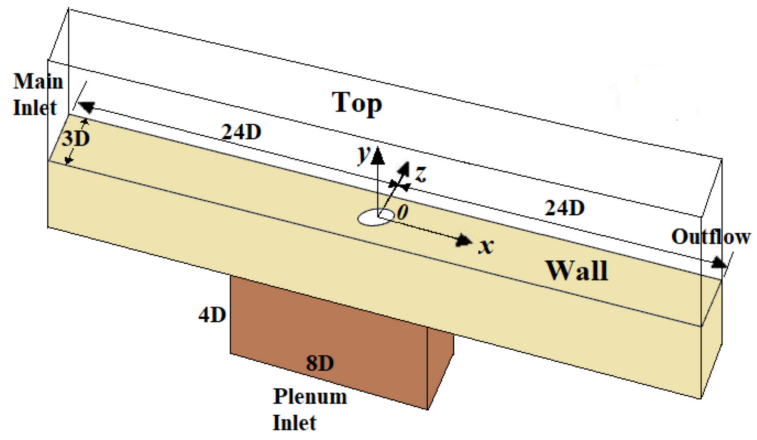

(b)

Figure 2. Computational domain configuration. (a) Cylindrical hole, $\beta=0^{\circ}$; (b) Cylindrical hole, $\beta=30^{\circ}$.

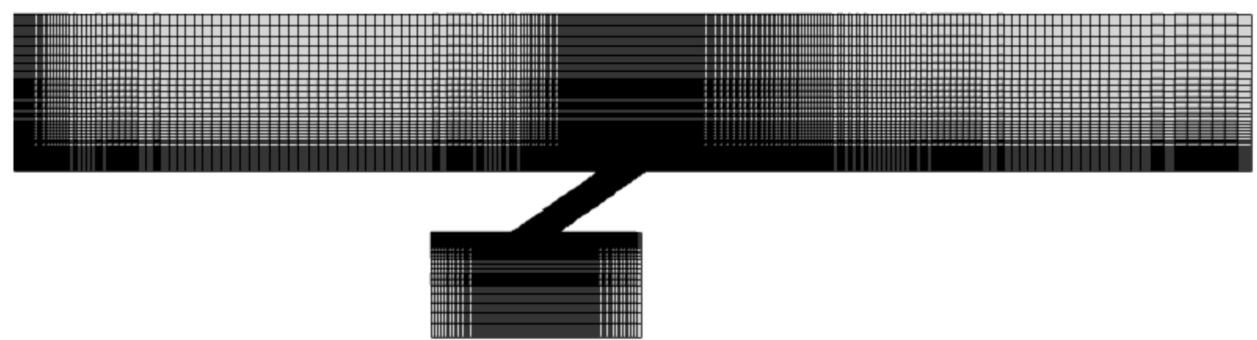

(a)

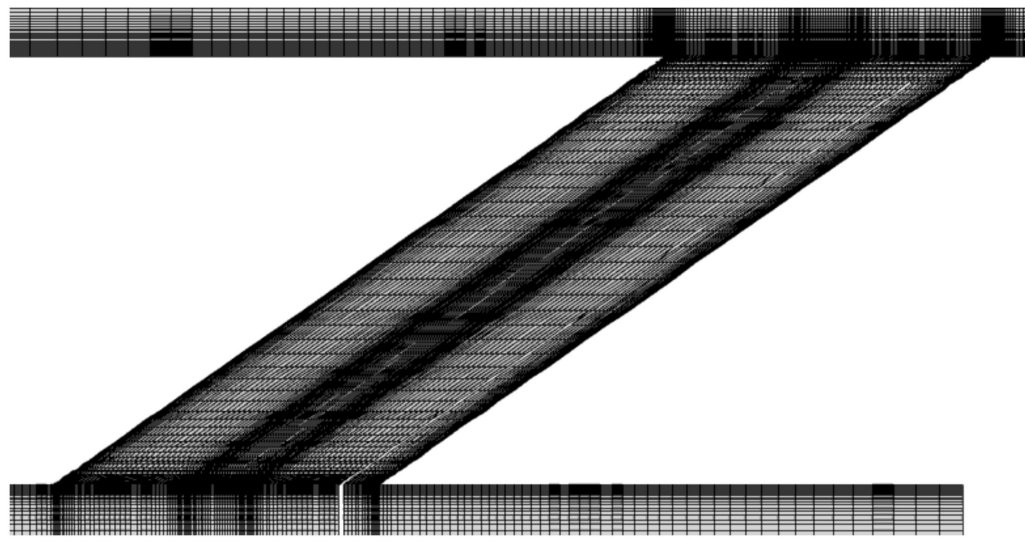

(b)

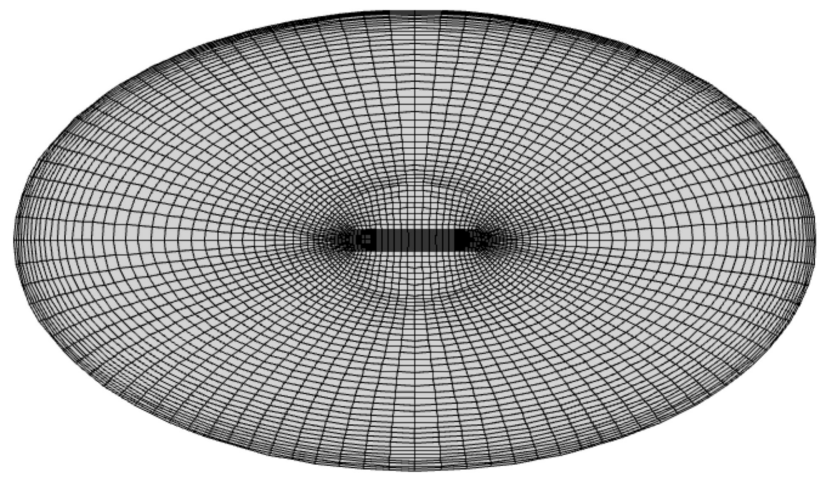

(c)

Figure 3. CFD meshes of the cylindrical hole: (a) overall view of the mesh on the $z=0$ plane; (b) close-up of the grid around the hole; (c) Close-up of the grid at the hole exit. 


\subsubsection{Unsteady RANS Approach}

For a $36 \mathrm{~Hz}$ pulsation, the unsteady RANS (URANS) method was used since unsteady flow structures can be predicted by URANS. According to Jung [17], coolant Strouhal number is between 0.2 and 6.0 for operating transonic gas turbines, and they discussed the effects of sinusoidal pulsations in the main flow at a frequency of $36 \mathrm{~Hz}(S t=3.62)$ on film cooling. For comparison with the experimental data, $36 \mathrm{~Hz}$ pulsation was chosen.

Conservation of mass:

$$
\frac{\partial}{\partial x_{j}}\left(U_{j}\right)=0
$$

Conservation of momentum:

$$
\rho\left(\frac{\partial U_{i}}{\partial t}+U_{j} \frac{\partial U_{i}}{\partial x_{j}}\right)=-\frac{d p}{d x_{i}}+\rho g \delta_{i 3}+\frac{\partial}{\partial x_{j}}\left(\mu \frac{\partial U_{i}}{\partial x_{j}}-\rho \overline{u_{i} u_{j}}\right)
$$

Conservation of energy:

$$
\rho c_{p}\left(\frac{\partial \bar{T}}{\partial t}+U_{j} \frac{\partial \bar{T}}{\partial x_{j}}\right)=-\frac{\partial}{\partial x_{j}}\left(-\kappa \frac{\partial \bar{T}}{\partial x_{j}}+\rho c_{p} \overline{u_{j} T^{\prime}}\right)
$$

Six Reynolds stresses, $-\rho \overline{u u},-\rho \overline{u v},-\rho \overline{u w},-\rho \overline{v v},-\rho \overline{v w}$, and $-\rho \overline{w w}$, from Equation (2), and $\overline{T^{\prime} u}, \overline{T^{\prime} v}$, and $\overline{T^{\prime} w}$ from Equation (3) need to be modeled [22]. A closure for the equations could be obtained using the Boussinesq hypothesis, which is expressed as [20]

$$
-\rho \overline{u_{i}{ }^{\prime} u_{j}^{\prime}}=\mu_{t}\left(\frac{\partial u_{i}}{\partial x_{j}}+\frac{\partial u_{j}}{\partial x_{i}}-\frac{2}{3} \frac{\partial u_{k}}{\partial x_{k}} \delta_{i j}\right)-\frac{2}{3} \rho K \delta_{i j}
$$

where $\mu_{t}$, turbulent viscosity is defined as follows [22]:

$$
\mu_{t}=\frac{\rho C_{\mu} K^{2}}{\varepsilon}
$$

\subsubsection{LES Approach}

LES directly resolves eddies of large size; however, it models small eddies. Most mass, energy, and momentum are transported by the eddies of large size; thus, this approach is reasonable [23]. LES Navier-Stokes equations are expressed as follows [22]:

$$
\begin{gathered}
\frac{\partial \rho}{\partial t}+\frac{\partial}{\partial x_{i}}\left(\rho \bar{u}_{i}\right)=0 \\
\frac{\partial(\rho \bar{u})}{\partial t}+\frac{\partial}{\partial x_{j}}\left(\rho \bar{u}_{i} \bar{u}_{j}\right)=\frac{\partial}{\partial x_{j}}\left[\mu\left(\frac{\partial \overline{u_{i}}}{\partial x_{j}}+\frac{\partial \overline{u_{j}}}{\partial x_{i}}\right)-\frac{2}{3} \mu \frac{\partial \bar{u}_{l}}{\partial x_{l}} \delta_{i j}\right]-\frac{d \bar{p}}{d x}+\frac{\partial \tau_{i j}}{\partial x_{j}}
\end{gathered}
$$

The sub-grid scale turbulent stress $\left(\tau_{i j}\right)$ needs to be modeled and the Boussinesq hypothesis is employed as in [22].

$$
\tau_{i j}-\frac{1}{3} \tau_{k k} \delta_{i j}=-\mu_{t}\left(\frac{\partial \overline{u_{i}}}{\partial x_{j}}+\frac{\partial \overline{u_{j}}}{\partial x_{i}}\right)
$$

\subsubsection{Boundary Conditions}

The boundary conditions of the computational domain are shown in Table 1. The RANS computations converged to the $10^{-5}$ level for all the equations in about $15 \mathrm{~h}$ on 20 core clusters for each case. The turbulence intensity at the main flow inlet was set as $0.2 \%$ as in the study of Jung [17]. The vortex method as the fluctuating velocity algorithm was adopted at the main inlet, and 190 vortices were injected in the inlet plane to afford the turbulent inflow conditions. The temperatures at the main and plenum inlets were 293 and 
$313 \mathrm{~K}$, respectively, which is similar to those of Jung [17] because the equal heating of the coolant is easier than the equal heating of the main flow.

Table 1. Boundary conditions.

\begin{tabular}{cc}
\hline Surface & Boundary Condition \\
\hline Main inlet & Velocity inlet \\
Plenum inlet & Velocity inlet \\
Top & Symmetry \\
Test plate & Adiabatic wall \\
Outflow & Pressure outlet \\
Main sides & Periodic \\
Sides of plenum & Adiabatic wall \\
\hline
\end{tabular}

The velocity profile at the main inlet was spatially uniform. It was set as follows:

$$
V_{\text {main }}=A \sin (2 \pi f t)+10 \mathrm{~m} / \mathrm{s}
$$

The main flow velocity pulsation amplitudes, $A$ values, were taken from Jung [17]. The values are shown in terms of frequency and Strouhal number $(S t)$ in Table 2.

Table 2. Values in Equation (11) in terms of frequency and Strouhal number (St).

\begin{tabular}{ccc}
\hline Frequency $\mathbf{( H z )}$ & $\mathbf{0}$ & $\mathbf{3 6}$ \\
\hline$S t$ & 0 & 3.62 \\
$\beta$ & $0^{\circ}$ and $30^{\circ}$ & $0^{\circ}$ and $30^{\circ}$ \\
$\mathrm{A}$ & 0 & 0.54 \\
\hline
\end{tabular}

Moreover, the spatially uniform velocity profile is applied at the plenum inlet and it is set as

$$
V_{\text {plenum }}=B \sin (2 \pi f t)+0.164 \mathrm{~m} / \mathrm{s}
$$

where $0.164 \mathrm{~m} / \mathrm{s}$ corresponds to the velocity at $M=0.5$ for the steady state. If sinusoidal pulsation was applied to the main flow inlet, pulsation having the same frequency was generated in the injectant since the pulsation generates a pressure difference in the main flow between the static pressure around the hole inlet and around the hole exit. Therefore, in this study, sinusoidal pulsation with the same frequency were simultaneously applied for both inlets. The amplitudes of the plenum inlet velocity pulsation, $B$ values in terms of frequency were not reported; however, plots for the variation of the pressure difference at each frequency are given in Jung [17]. $B$ values were acquired by matching the plots using the trial and error method and the $B$ values are shown in Table 3. When pulsation of $36 \mathrm{~Hz}$ is applied to the inlets, the amplitude of the pressure difference increases since large phase shifts [14]. Consequently, the coolant velocity pulsation amplitude increases, causing the periodic generation of more cooling air jet lift off and decreasing the film cooling effectiveness.

Table 3. $B$ values in Equation (11) in terms of frequency and Strouhal number (St).

\begin{tabular}{ccc}
\hline Frequency $\mathbf{( H z )}$ & $\mathbf{0}$ & $\mathbf{3 6}$ \\
\hline$S t$ & 0 & 3.62 \\
$\beta$ & $0^{\circ}$ and $30^{\circ}$ & $0^{\circ}$ and $30^{\circ}$ \\
$B$ & 0 & 0.3 \\
\hline
\end{tabular}

\subsection{Validation of Numerical Methods}

ANSYS Fluent [22] was used for numerical calculations, and Pointwise [24] was used to make the meshes. CFD simulations were performed using LES, RANS, and URANS. 
The computational results were validated with the experimental data from Jung [17]. The Smagorinsky-Lilly model was adopted as the sub-grid scale model, and the realizable $k-\varepsilon$ model was adopted for RANS and URANS, since it exhibits the least difference with the experimental data [25]. For LES simulation, the time step was set at $5.55 \times 10^{-6} \mathrm{~s}$, which corresponds to the time needed for the main flow to convect the length of $D$ with 360 time steps [26,27]. For URANS simulation, the time step was set as $5.55 \times 10^{-4} \mathrm{~s}$, which corresponds to the period for $36 \mathrm{~Hz}$ pulsation divided by 50 . For each iteration, about 10 sub-iterations were carried out to ensure that the numerical data were well resolved and to decrease the linearization and factorization errors [22]. Twenty cores of Intel Xeon Gold 6148 were employed, and the computation times for LES and RANS calculations were about 8 weeks and less than $10 \mathrm{~h}$, respectively. Figure 4 shows the plots of the centerline effectiveness for mesh sensitivity test at $0 \mathrm{~Hz}$ for the blowing ratio of $M=0.5$ using the LES Smagorinsky-Lilly model. Five different meshes were tested, and the specifications for each mesh are indicated in Table 4 . The first mesh did not have sufficient resolution to accurately reproduce the flow structures of the film cooling compared to other meshes. The third grid with 2.04 million cells showed almost the same $\eta_{c}$ as the grids of the fourth and fifth. Thus, the grid with 2.04 million hexahedrons was chosen for the numerical simulations. The mesh spacing values ranged from 6 near the cooling hole to around 35 at $x / D=24$ in $x^{+}$unit in the $x$ direction. The $y^{+}$value for the first cell above the test plate was less than two to capture the gradient of the test plate normal velocity in the viscous sublayer, and twenty five cell layers were present up to $y^{+}=30$. The ratio of instantaneous subgrid turbulent viscosity to the molecular viscosity was lower than 0.3966 at the exit of the hole in LES simulation.

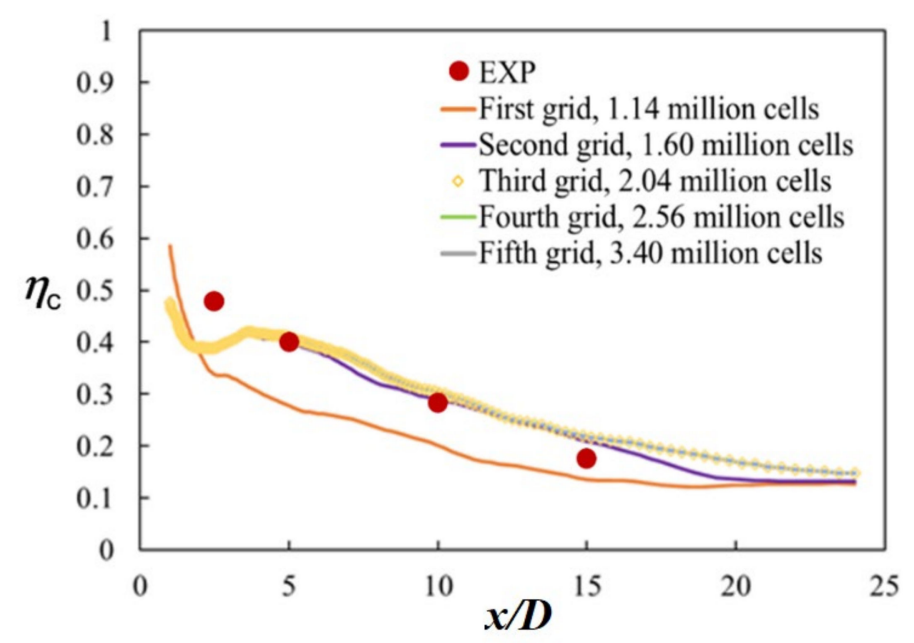

Figure 4. Result of mesh sensitivity test using the LES.

Table 4. Specifications of grid arrangements for grid sensitivity test.

\begin{tabular}{cccccc}
\hline Grid & $\begin{array}{c}\text { \# of Cells in the } \boldsymbol{x} \\
\text { Direction }\end{array}$ & $\begin{array}{c}\text { \# of Cells in the } y \\
\text { Direction }\end{array}$ & $\begin{array}{c}\text { \# of Cells in the } z \\
\text { Direction }\end{array}$ & $\begin{array}{c}\text { \# of Cells in the Main Block } \\
\text { (Million) }\end{array}$ & $\begin{array}{c}\text { Total \# of Cells } \\
\text { (Million) }\end{array}$ \\
\hline First & 242 & 52 & 34 & 0.5 & 1.14 \\
Second & 248 & 62 & 52 & 0.96 & 1.60 \\
Third & 276 & 80 & 56 & 1.41 & 2.04 \\
Fourth & 298 & 94 & 60 & 2.76 & 2.56 \\
Fifth & 312 & 110 & 68 & & 3.40 \\
\hline
\end{tabular}

\# represents the number. 


\section{Results and Discussion}

\subsection{Spanwise-Averaged Film Cooling Effectiveness}

Figure 5 illustrates the plots of the time-averaged $\eta_{m}$ for the orientation angle $\beta$ of $0^{\circ}$ and $30^{\circ}$ under steady state and flow pulsation of $36 \mathrm{~Hz}$ obtained using LES, RANS $(0 \mathrm{~Hz})$, and URANS $(36 \mathrm{~Hz})$ as a function of $x / D$ for the time-averaged blowing ratios of 0.5. The numerical results were validated with the experimental results from Jung [17]. At the steady state, as the main flow went downstream, the spanwise-averaged effectiveness decreased because the dimensionless temperature of the coolant film decreased due to the turbulence generation and the mixing between the cross flow and injectant. If the pulsation frequency went from 0 to $36 \mathrm{~Hz}, \eta$ decreased regardless of the compound angle; however, the film cooling for the orientation angle of $30^{\circ}$ displayed better performance than that for a simple angle.

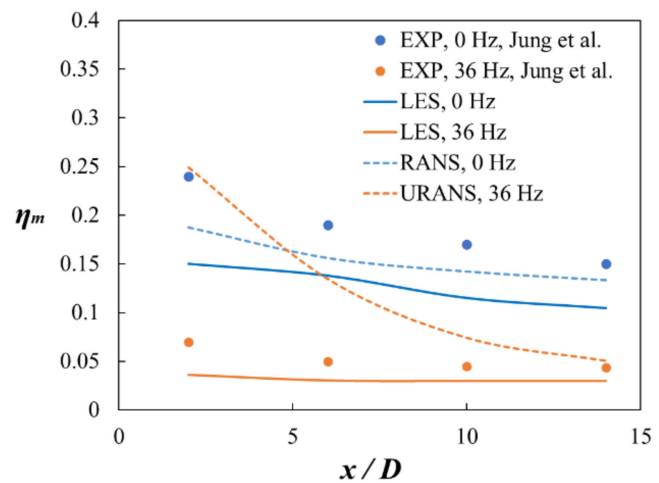

(a)

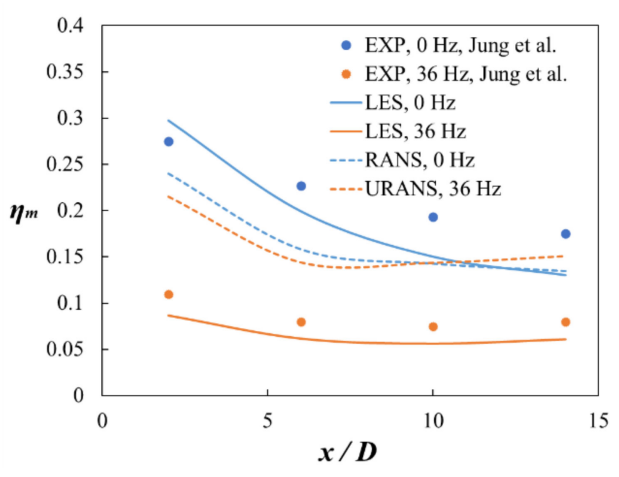

(b)

Figure 5. Time-and spanwise-averaged effectiveness at 0 and $36 \mathrm{~Hz}$ as a function of $x / D$. (a) Simple angle $\left(\beta=0^{\circ}\right) ;(\mathbf{b})$ Compound angle $\left(\beta=30^{\circ}\right)$.

Although the LES and RANS models slightly underpredicted the spanwise-averaged effectiveness, Figure 5a illustrates that $\eta_{m}$ for the $0^{\circ}$ (simple angle) orientation angle at the steady state $(0 \mathrm{~Hz})$ obtained by LES and RANS matched the experimental data with an acceptable accuracy. As observed, the spanwise-averaged effectiveness obtained by RANS slightly deviated from that obtained by LES and the experimental data under the steady state. Under a $36 \mathrm{~Hz}$ flow pulsation, LES still slightly underpredicted the spanwise-averaged film cooling effectiveness, while URANS drastically overpredicted the effectiveness and demonstrated a large deviation with the experimental data, especially in the narrow region; however, in the downstream region, the deviation between the URANS results and the experimental results became almost zero. Thus, the use of LES is recommended over the use of URANS to obtain the film cooling effectiveness under unsteady flow.

A distinct feature in Figure $5 \mathrm{~b}$ is that for the orientation angle $\beta=30^{\circ}$, LES predicted the film cooling effectiveness considerably better than RANS for both the steady state and the $36 \mathrm{~Hz}$ pulsation. Unlike Figure $5 \mathrm{a}$, in the downstream region, RANS overpredicted $\eta$ for the $36 \mathrm{~Hz}$ pulsation. The average difference in $\eta_{m}$ between the experimental data and LES results was approximately $8 \%$, while the difference between the experimental results and RANS results was approximately $23 \%$ for the steady state. Moreover, for the $36 \mathrm{~Hz}$ flow pulsation, the average difference in the spanwise-averaged effectiveness between the experimental results and LES results was approximately $22 \%$, while that between the experimental data and RANS results was approximately $89 \%$. The deviations were mostly attributed to the low mixing between the cross flow and injectant than that in the experiment.

Since the deviations between the LES results and experimental data at steady state were similar to those between the RANS results and experimental results, RANS could be a good alternative for predicting the spanwise-averaged effectiveness for cylindrical 
holes. Although RANS overpredicted $\eta$ in the centerline of the cooling air spreading, it underpredicted the core jet dissipation and lateral spreading of the injectant. Therefore, $\eta_{m}$ predicted by RANS became similar to the experimental results.

\subsection{Distribution of the Time-Averaged Film Cooling Effectiveness at $x / D=5$}

Figure 6 illustrates the distribution of the time-averaged $\eta$ for the orientation angle $\beta$ of $0^{\circ}$ and $30^{\circ}$ at the line of $x / D=5$ for the time-averaged blowing ratios of 0.5 . Although $\eta_{m}$ at the steady state obtained by RANS agreed with the experimental data with an acceptable accuracy (Figure 5), the local distributions of $\eta$ in the spanwise direction predicted by the RANS simulations did not match the experimental data (Figure 6). RANS significantly overpredicted $\eta$, especially around the centerline of the coolant spreading, whereas LES afforded more accurate predictions for the local film cooling effectiveness, indicating that the mixing intensity between the injectant and main flow for RANS was low. Spreading of the cooling air in the spanwise direction predicted by RANS did not match that for the experimental data.

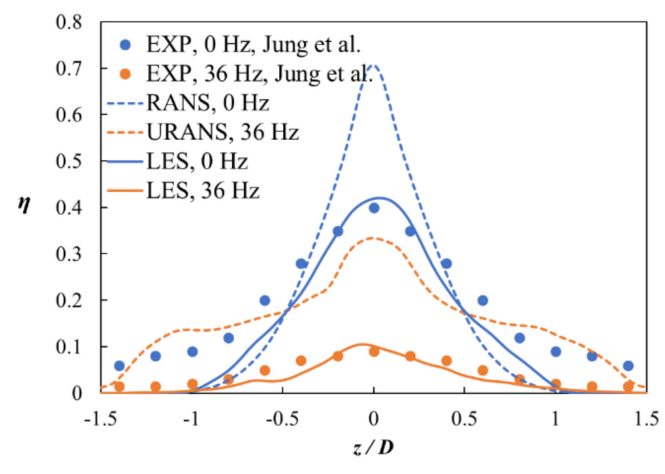

(a)

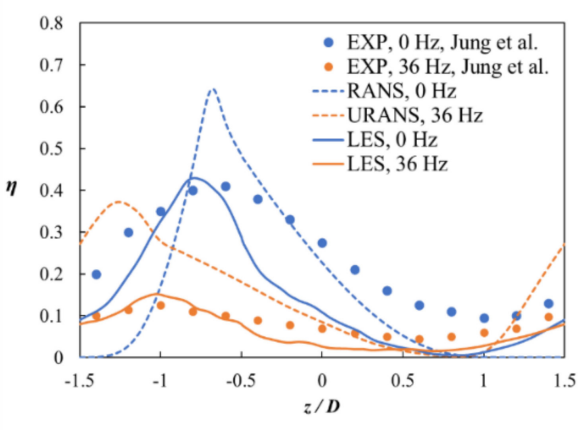

(b)

Figure 6. Distribution of the time-averaged $\eta_{m}$ at $x / D=5$. (a) Simple angle $\left(\beta=0^{\circ}\right)$; (b) Compound angle, $\beta=30^{\circ}$.

The location of the local peak of the effectiveness obtained by RANS was biased in the spanwise direction compared to the experimental results, and the LES results better matched the experimental data under $36 \mathrm{~Hz}$ flow pulsation than under steady state. The average difference in the spanwise effectiveness for the orientation angle $\beta$ of $0^{\circ}$ between the experimental results and LES results was approximately $15 \%$, while that between the experimental results and URANS results was approximately $176 \%$ for the $36 \mathrm{~Hz}$ pulsation. Considering the danger of poor local cooling on the turbine blade, LES should be performed instead of RANS to obtain the local $\eta$ for a cylindrical hole with a compound angle on turbine blades, even though the computational cost of LES is considerably higher than that of RANS.

\subsection{Time-Averaged Film Cooling Effectiveness Contours}

Figure 7 illustrates the contours of the time-averaged $\eta$ on the wall for the orientation angle $\beta$ of $0^{\circ}$ and $30^{\circ}$ obtained by LES and RANS models for the steady state and $36 \mathrm{~Hz}$ flow pulsation for the time-averaged blowing ratio of 0.5 . They were compared to the contours obtained using the experimental data [17]. At the steady state, the RANS contours overpredicted $\eta$ regardless of the compound angle, especially around the centerline of the coolant spreading in the narrow region, where $x / D$ was less than five due to the low mixing between the injectant and main flow. The LES contours showed that the spread of injectant in the spanwise direction on the wall was higher than that of the RANS results; additionally, the coolant spreading in the LES contours was smaller than that in the experimental contours. 
$0 \mathrm{~Hz}$

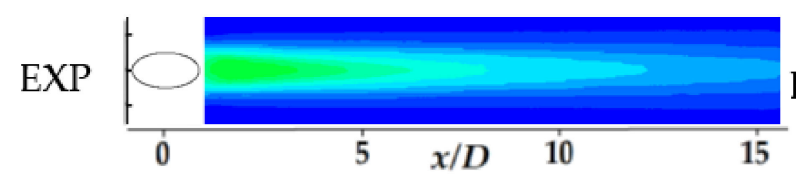

$36 \mathrm{~Hz}$

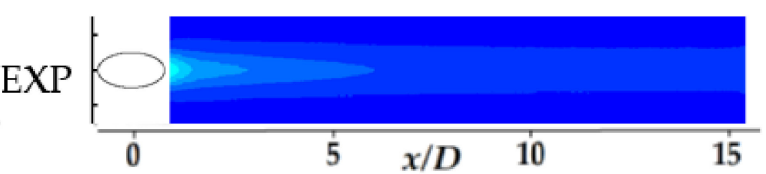

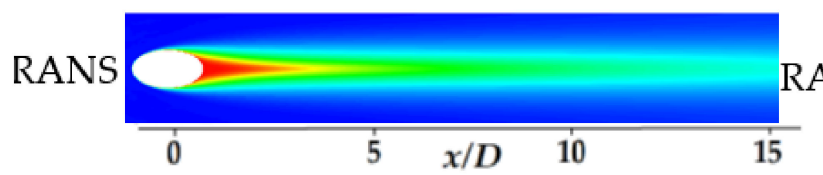

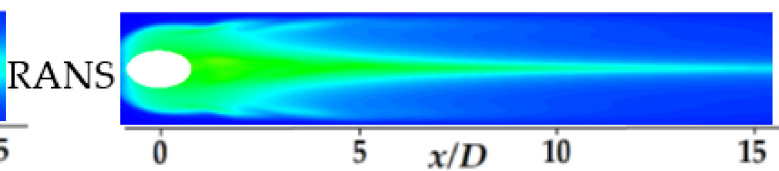

LES
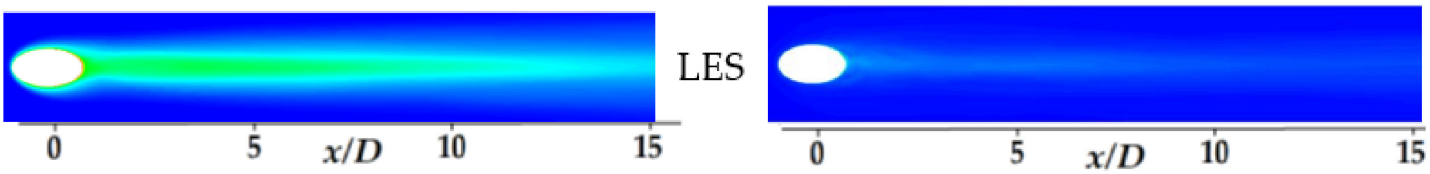

(a)

$0 \mathrm{~Hz}$
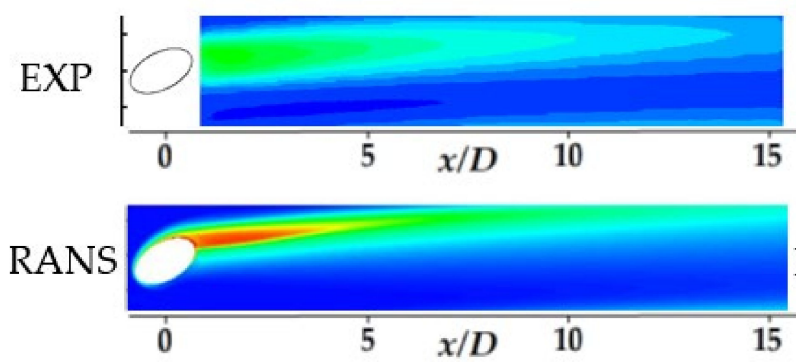

LES

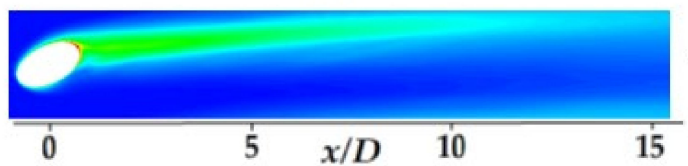

$36 \mathrm{~Hz}$

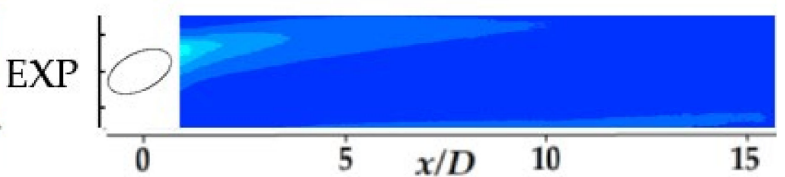

(b)

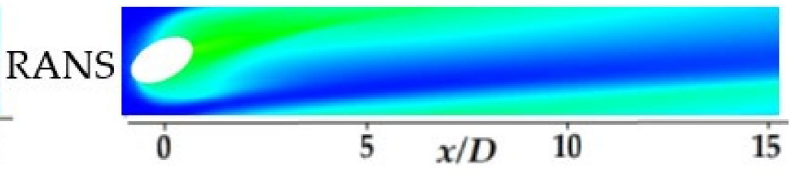

LES
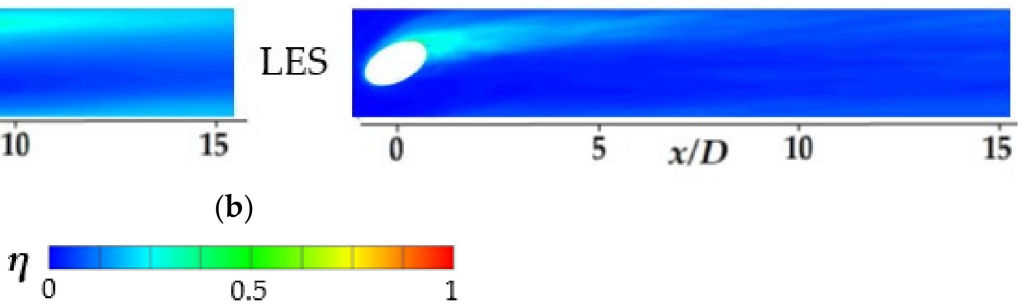

Figure 7. Contours of time-averaged film cooling effectiveness on the wall at steady state and $36 \mathrm{~Hz}$ pulsation. (a) Simple angle $\left(\beta=0^{\circ}\right) ;(\mathbf{b})$ Compound angle.

In the steady state, the horseshoe vortex was clearly displayed in the LES contours, whereas the vortex was not clearly displayed in the URANS contours. Under the $36 \mathrm{~Hz}$ flow pulsation, the contour predicted by RANS largely deviated from the experimental contour or LES contour, as seen in Figure 7. The figure demonstrates that the RANS overpredicted the cooling spreading compared to the experimental data or LES.

\subsection{Time-Averaged Dimensionless Temperature Contours on the Streamwise-Normal Planes}

Figure 8 illustrates the time-averaged dimensionless temperature contours on the streamwise-normal planes of $x / D=2.5,5$, and 10 for the orientation angle $\beta$ of $0^{\circ}$ obtained using the experimental data [17], LES, RANS, and URANS methods under steady state and $36 \mathrm{~Hz}$ pulsation at time-averaged blowing ratio of 0.5 . Figure $8 \mathrm{a}-\mathrm{c}$, which illustrate the contours for the simple angle at the steady state, show that the shape of the coolant predicted by LES was more similar to the contours of the experimental data than that predicted by RANS, even though the maximum dimensionless temperature of the coolant core part predicted by RANS was close to that obtained by LES or experimental data. The location of the core part of the coolant jet in the RANS contours was close to the wall, in contrast to that in the LES or experimental contours, because the mixing with the main flow was low in the RANS contours. Thus, the dimensionless temperature around $z / D=0$ was higher than that of the experimental results, and this explains why the adiabatic film 
cooling effectiveness was overpredicted in the RANS approach around the centerline of the coolant spreading. In the experimental data, no data existed near the wall since the data near the wall could not be obtained through measurement using the cold wire. However, LES contours showed that the location of the core part of the coolant jet was not close to the wall. As shown in Figure $8 \mathrm{~d}-\mathrm{f}$, under the $36 \mathrm{~Hz}$ flow pulsation, the coolant shape predicted by LES for the orientation angle $\beta$ of $30^{\circ}$ was more similar to that predicted by the experimental data than RANS. Unlike the contours in Figure 8a-c, the dimensionless temperature of the coolant core part obtained by RANS was considerably higher than that obtained by LES or experimental data, indicating significantly less mixing between the coolant and main flow under pulsation. In contrast, the dimensionless temperature contour predicted by LES was similar to that of the experimental data. As shown in the streamlines of Figure 8 for the simple angle, CRVP was clearly observed for the $36 \mathrm{~Hz}$ pulsation and the steady state. Moreover, as the main flow went downstream, the size of the CRVP predicted by LES and RANS increased; however, the intensity of the vortex weakened because of the dispersion of the cooling air due to the mixing between the main flow and coolant jet.

\section{(a) $\mathrm{x} / \mathrm{D}=2.5 \quad 0 \mathrm{~Hz}$}

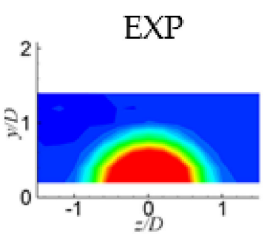

(b) $x / D=5$

EXP

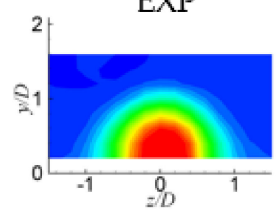

(c) $x / D=10$

EXP
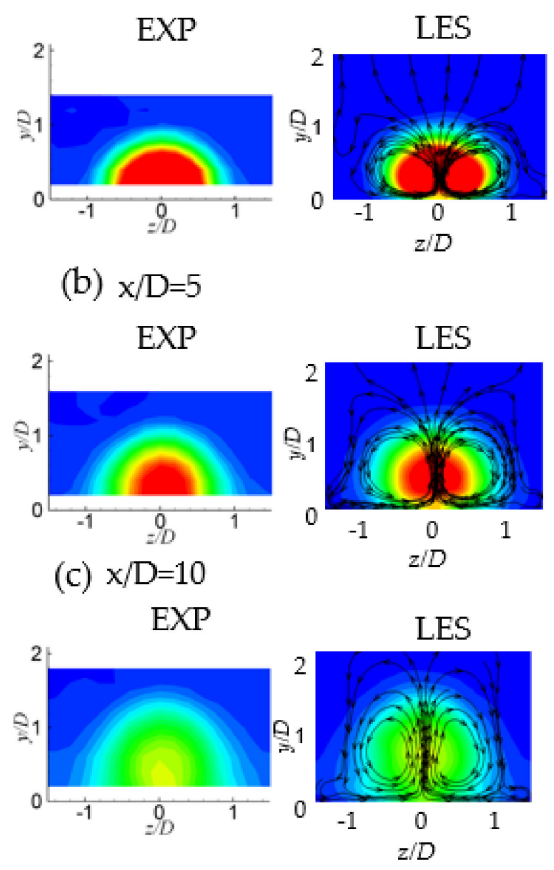

LES

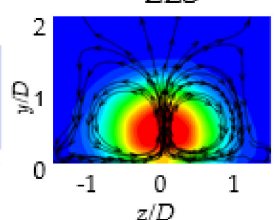

$z / D$

LES (d) $x / D=2.5$

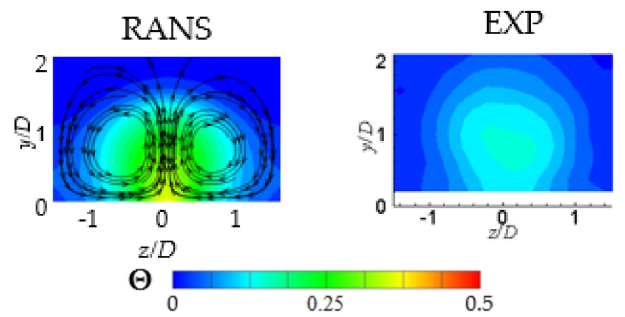

RANS

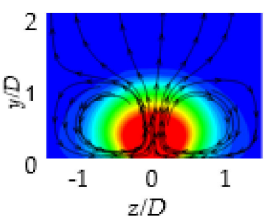

RANS

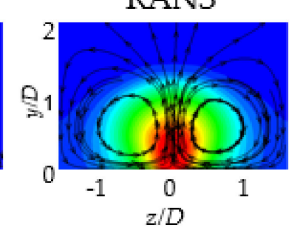

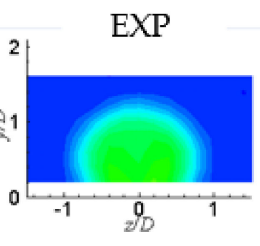

(e) $x / D=5$

EXP

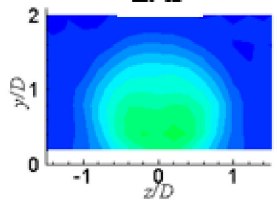

(f) $x / D=10$

EXP
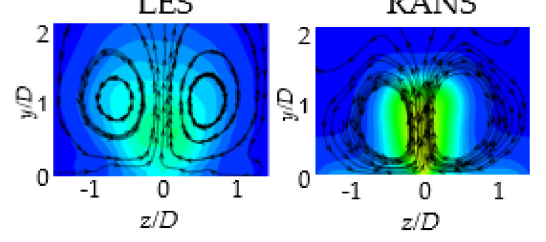

Figure 8. Time-averaged dimensionless temperature contours and streamlines for the orientation angle of $0^{\circ}$ on the plane of $x / D=2.5,5$, and 10 at steady state $(0 \mathrm{~Hz})$ and $36 \mathrm{~Hz}$ pulsation.

Figure 9 illustrates the contours of the time-averaged dimensionless temperature at $x / D=2.5,5$, and 10 for the orientation angle $\beta$ of $30^{\circ}$ obtained by the experimental data [17], LES, RANS, and URANS at the steady state $(0 \mathrm{~Hz})$ and $36 \mathrm{~Hz}$ pulsation. Due to the compound angle, CRVP changed to a single vortex, and the coolant shape inclined, as illustrated in the streamlines and contours. Under the steady state, the dimensionless temperature of the coolant core part obtained by RANS was similar to that obtained by LES or the experimental data, even though the location of the region of the coolant core part was close to $z / D=0$. Moreover, under the $36 \mathrm{~Hz}$ flow pulsation, the dimensionless temperature of the coolant core obtained by RANS was higher than that obtained by LES and the experimental data. In the streamlines, as the flow went downstream, the size of the single vortex predicted by LES and RANS increased due to coolant dispersion and mixing; however, the intensity of the vortex weakened. 


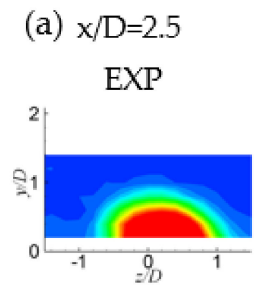

(b) $x / D=5$

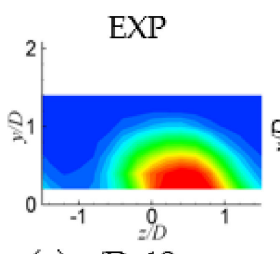

(c) $x / D=10$

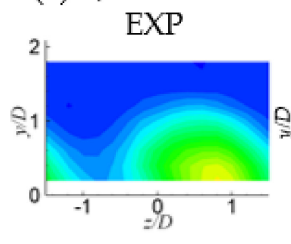

$0 \mathrm{~Hz}$

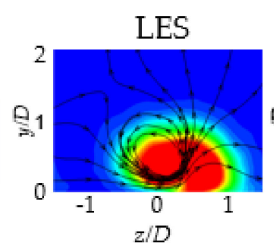

LES

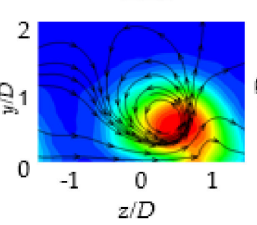

LES

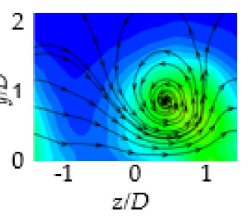

(d) $x / D=2.5$

EXP

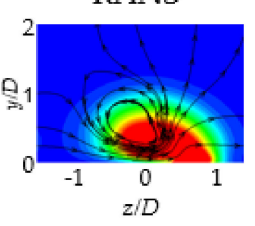

RANS

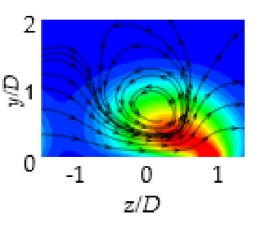

RANS

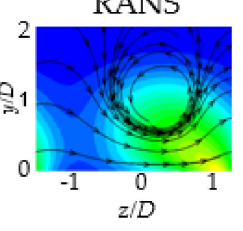

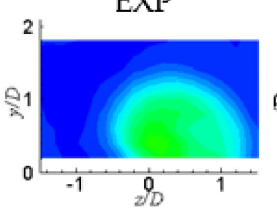

(e) $x / D=5$

EXP

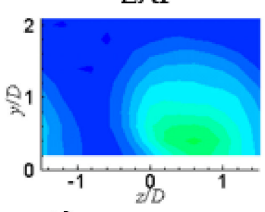

(f) $x / D=10$

EXP

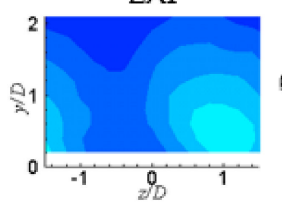

$36 \mathrm{~Hz}$
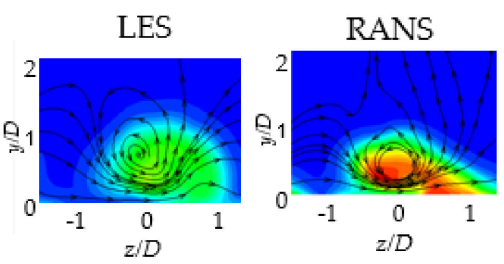

LES

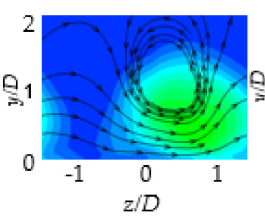

LES

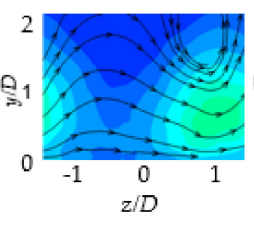

RANS

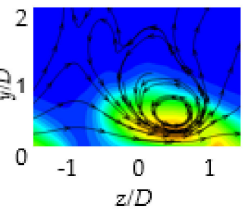

RANS

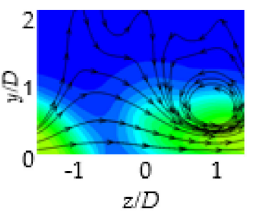

$\Theta$

0.25

0.5

Figure 9. Time-averaged dimensionless temperature contours and streamlines for the orientation angle of $30^{\circ}$ on the plane of $x / D=2.5,5$, and 10 at steady state $(0 \mathrm{~Hz})$ and $36 \mathrm{~Hz}$ pulsation.

\subsection{Contours of Phase-Averaged Dimensionless Temperature at $x / D=5$}

Figure 10 displays the phase-averaged dimensionless temperature contours and streamlines for the orientation angles of $0^{\circ}$ and $30^{\circ}$ under the $36 \mathrm{~Hz}$ flow pulsation at $t / \tau=0.2,0.4,0.6$, and 0.8 on the plane of $x / D=5$ obtained using the experimental data [17], LES, RANS, and URANS at the time-averaged blowing ratio of 0.5. The coolant shape in the dimensionless temperature contours obtained by RANS differed from that obtained by the experimental data regardless of the compound angle, while that obtained by LES was quite similar to that obtained by the experimental data even though the temperature of the coolant core part predicted by LES was higher than that in the experimental data. This is because the injectant lift off and many vortices such as CRVP that were generated by the coolant injection were much better obtained by LES than RANS. Moreover, LES predicted the mixing between the cross flow and the injectant considerably better than RANS.

The dimensionless temperature contours predicted by LES better reflected the characteristics of the injectant concentration distributions at each phase in the experimental data than RANS. The change of the distributions was attributable to periodic changes of the blowing ratio, as shown in Equation (10), affording periodic variation of the injection velocity of the coolant. The phase-averaged dimensionless temperature contours obtained by LES in Figure 10 were predicted by averaging fifty instantaneous contours. At $t / \tau=0.4$ for the orientation angle of $0^{\circ}$ and at $t / \tau=0.6$ for the orientation angle of $30^{\circ}$, observing the coolant in the contour was difficult due to the negative blowing ratio according to Equation (10). When the instant blowing ratio was negative, the hot main flow was ingested into the hole, and it could damage the hole due to its high temperature. 

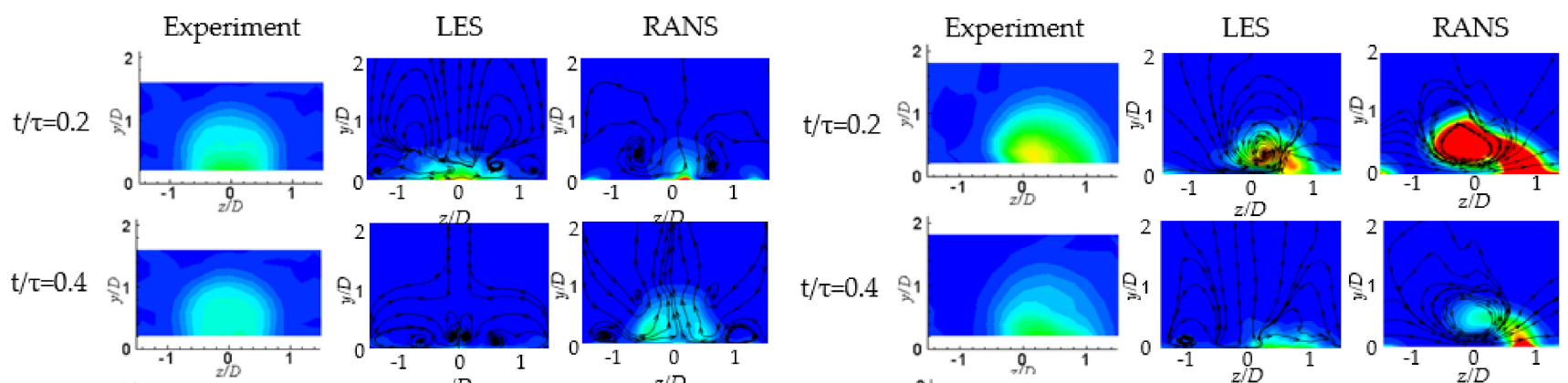

$t / \tau=0.6$
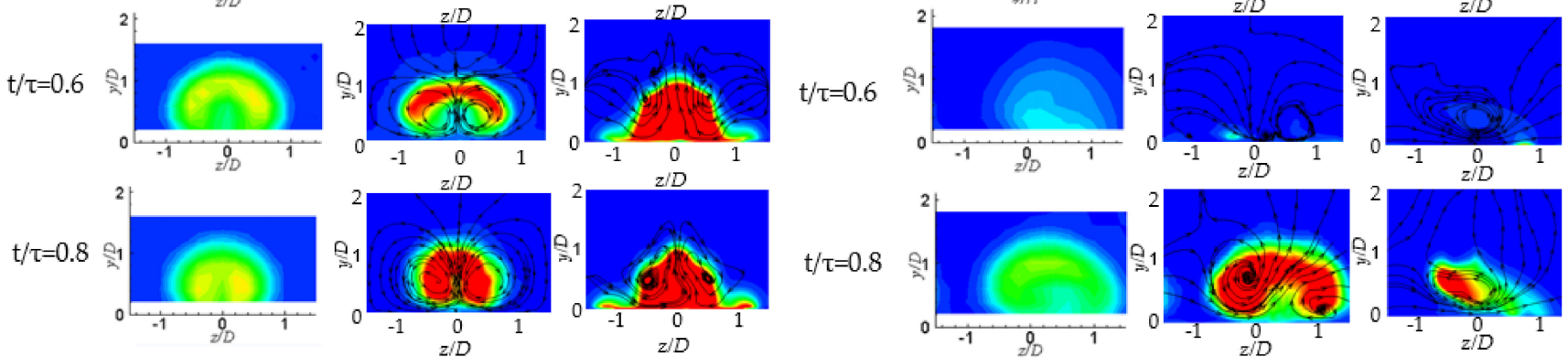

(a)

$\Theta$

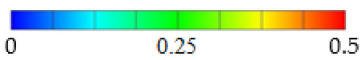

(b)

Figure 10. Phase-averaged dimensionless temperature contours and streamlines for the orientation angle of $0^{\circ}$ and $30^{\circ}$ on the plane of $x / D=2.5,5$, and 10 for the flow pulsation of $36 \mathrm{~Hz}$. (a) Simple angle $\left(\beta=0^{\circ}\right)$; (b) Compound angle, $\beta=30$.

In the streamlines for the $0^{\circ}$ orientation angle, CRVP was clearly observed in the LES and URANS results, except at $t / \tau=0.4$. The coolant shape in the dimensionless temperature contours obtained by RANS was not similar to that obtained by the experimental data or LES. However, CRVP was clearly observed in the URANS results. In the streamlines for the $30^{\circ}$ orientation angle, an almost single vortex was clearly observed in LES and URANS contours except at $t / \tau=0.4$ and 0.6 . When the $30^{\circ}$ orientation angle $(\beta)$ was adopted and the coolant was injected at a spanwise velocity, $\eta$ was improved as lateral spreading of the coolant on the wall was promoted and CRVP became asymmetric and weakened. If the CRVP effect decreased, the entrainment of the cross flow under the injectant was weakened, which afforded an increased and more uniform coolant coverage.

\subsection{Instantaneous Dimensionless Temperature Contours for the $30^{\circ}$ Orientation Angle on the Spanwise-Normal Plane}

Figure 11 shows the instantaneous dimensionless temperature contours for the $0^{\circ}$ orientation angle on the spanwise-normal plane of $z / D=0$ at $t / \tau=0.2,0.4,0.6,0.8$, and 1.0 for the $36 \mathrm{~Hz}$ pulsation at time-averaged $M$ of 0.5 obtained by LES and URANS. The figure displays the periodic injectant lift off and formations of large vortices of the coolant. According to Equation (10), the large vortices are generated when the instantaneous blowing ratio is almost maximum.

Figure 12 shows the instantaneous dimensionless temperature contours for the $30^{\circ}$ orientation angle on the spanwise-normal plane of $\mathrm{z} / \mathrm{D}=0.425 \mathrm{at} \mathrm{t} / \tau=0.2,0.4,0.6,0.8$, and 1.0 for the $36 \mathrm{~Hz}$ pulsation at the time-averaged blowing ratio of 0.5 obtained by LES and URANS. In the film cooling flow field for the $30^{\circ}$ orientation angle, the coolant was injected in the spanwise z-direction. Thus, capturing periodic coolant jet lift off on the plane of $\mathrm{z} / \mathrm{D}=0$ was difficult, and to investigate the temperature contours for the $30^{\circ}$ compound angle, contours on the spanwise-normal plane of $\mathrm{z} / \mathrm{D}=0.425$ were used. 
LES
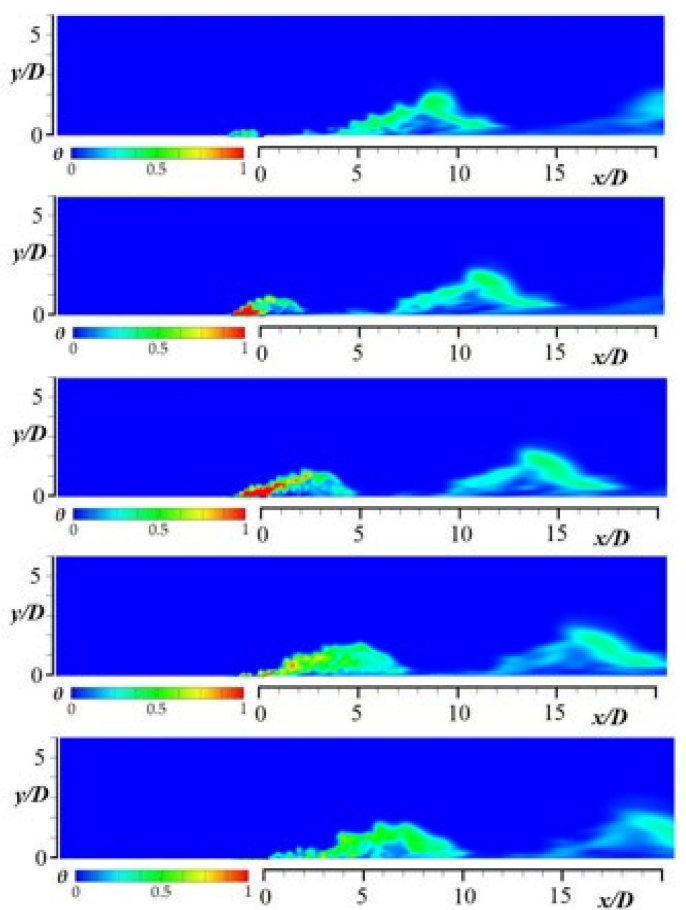

RANS

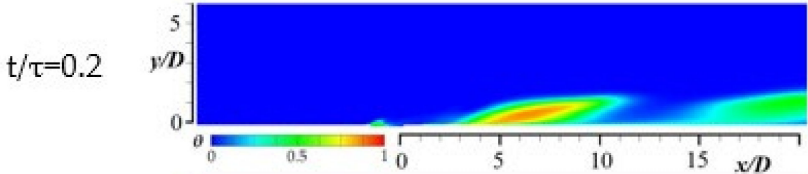

$t / \tau=0.4$

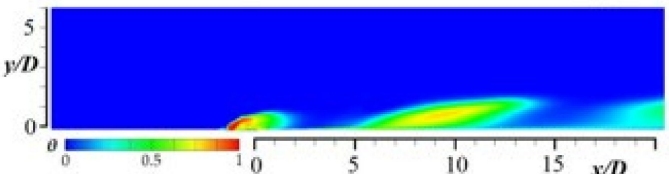

$t / \tau=0.6$

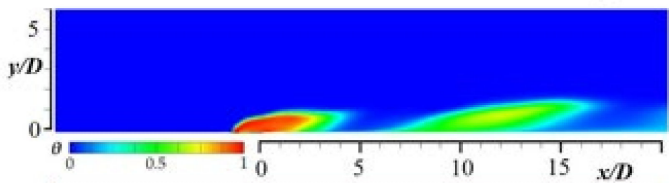

$t / \tau=0.8$

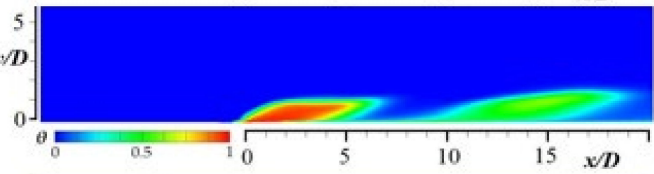

$t / \tau=1.0$

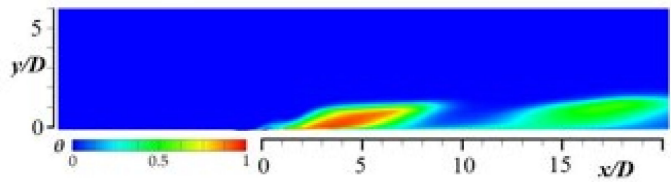

Figure 11. Instantaneous dimensionless temperature contours for the $0^{\circ}$ orientation angle on the spanwise-normal plane of $z / D=0$ for the $36 \mathrm{~Hz}$ flow pulsation.

\section{LES}
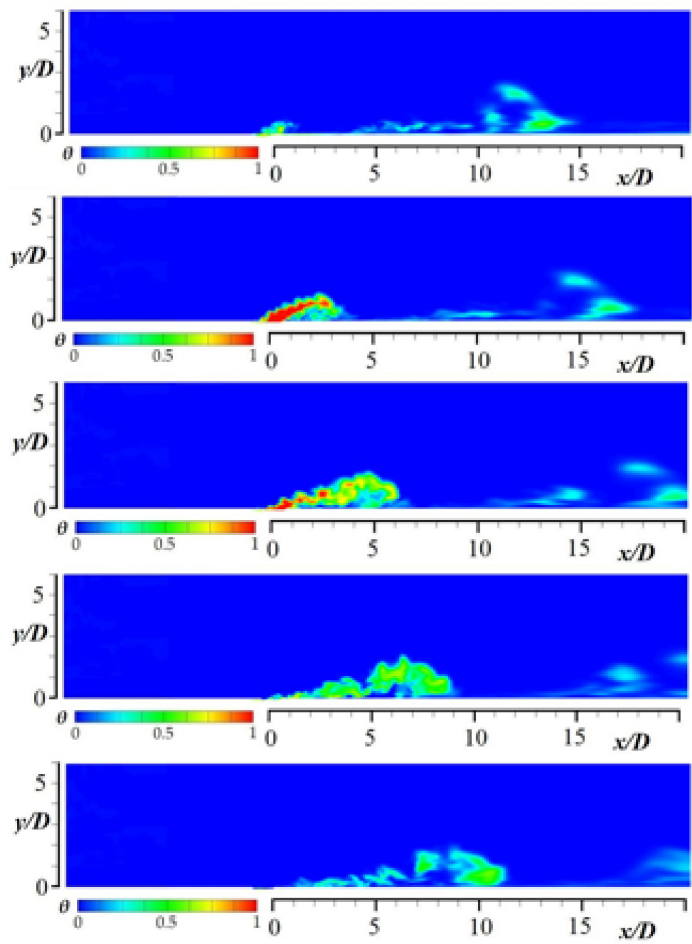

RANS

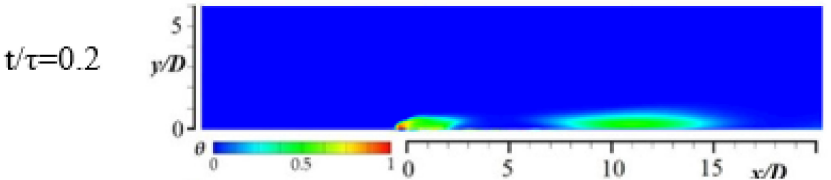

$t / \tau=0.4$

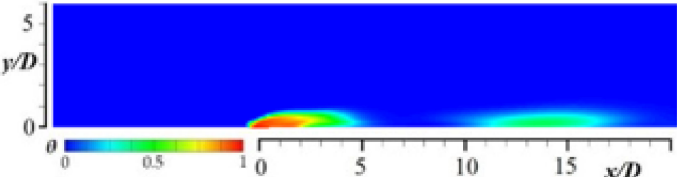

$t / \tau=0.6$

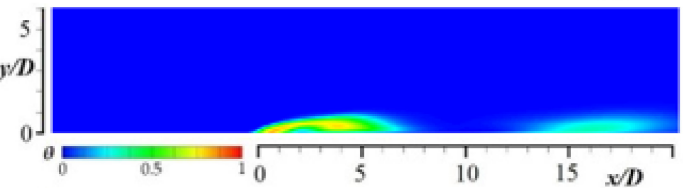

$t / \tau=0.8$

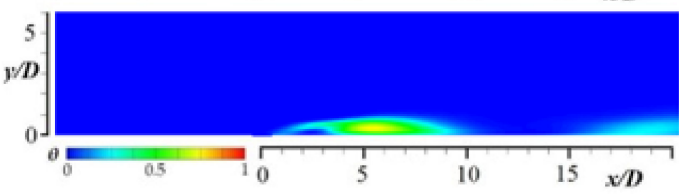

$t / \tau=1.0$

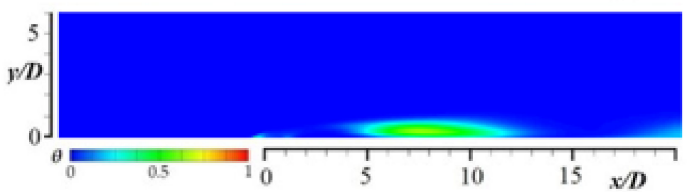

Figure 12. Instantaneous dimensionless temperature contours for the $30^{\circ}$ orientation angle on the spanwise-normal plane of $z / D=0.425$ for the $36 \mathrm{~Hz}$ flow pulsation.

The jet shear layer vortices generated by the shear between the cross flow and injectant were found on the LES contour at $t / \tau$ of 0.4 and 0.6 for the orientation angles of $0^{\circ}$ and $30^{\circ}$, 
while the vortices were not seen in the URANS contours. Both LES and RANS contours illustrated intermittent coolant injection. However, in the LES contours, the coolant jet lift off was clearly observed when the instantaneous blowing ratio was high, while in the RANS contours, the jet lift off was not clearly observed, and the coolant remained close to the wall, which increased the film cooling effectiveness predicted by RANS. Thus, as seen in Figure $5 b, \eta_{m}$ obtained by RANS was overpredicted, and the average difference in the spanwise-averaged effectiveness between the experimental data and RANS was approximately $89 \%$ for the $36 \mathrm{~Hz}$ pulsation.

In the contours for the $30^{\circ}$ orientation angle in Figure 12, the intensity of the coolant lift off was weaker than that in the contours for the $0^{\circ}$ orientation angle in Figure 11 because the compound angle improved the lateral spreading of the coolant and weakened the effect of the jet lift off.

\subsection{Instantaneous Film Cooling Effectiveness Contours on the Wall}

Figure 13 displays the contours of the instantaneous film cooling effectiveness on the wall obtained by LES for the $0^{\circ}$ and $30^{\circ}$ orientation angles under steady state and $36 \mathrm{~Hz}$ flow pulsation. For the steady state, $t^{*}$ represents the dimensionless time defined by the main flow velocity and $D ; t^{*}=1$ is the time that the main flow covers a distance equivalent to the hole diameter. Furthermore, for the unsteady state, the instantaneous contours for $t / \tau=0,0.2,0.4,0.6$, and 0.8 are displayed.

As shown in Figure 13a, when an orientation angle $\beta$ of $30^{\circ}$ was adopted and the coolant was injected at a spanwise velocity at the steady state, the film cooling effectiveness was improved since the lateral spreading of the coolant on the wall was promoted and the CRVP became asymmetric and weakened. Thus, the entrainment of the hot cross flow under the injectant weakened, which yielded improved uniform coolant coverage, as illustrated in the figure.

When the pulsation of $36 \mathrm{~Hz}$ was applied to the flow inlet, lift-off and reattachment of coolant intermittently occurred, and the adiabatic film cooling effectiveness decreased regardless of the compound angle (Figure 13b). In the contours at $t / \tau=0.6$ for the simple angle, the film cooling periodically appeared around the rim of the hole due to the influence of the horseshoe and counter vortices [28-30]. In the contours for the $30^{\circ}$ orientation angle, the region of high $\eta$ periodically changed. Thus, $\eta$ was high in the narrow region at $t / \tau$ $=0$ and 0.2 as well as in the downstream region at $t / \tau=0.6$ and 0.8 . When the pulsation frequency in the cross flow went from 0 to $36 \mathrm{~Hz}$, the film cooling for the $30^{\circ}$ orientation angle exhibited better performance than that for the simple angle, as seen in the contours of the instantaneous $\eta$ distributions.
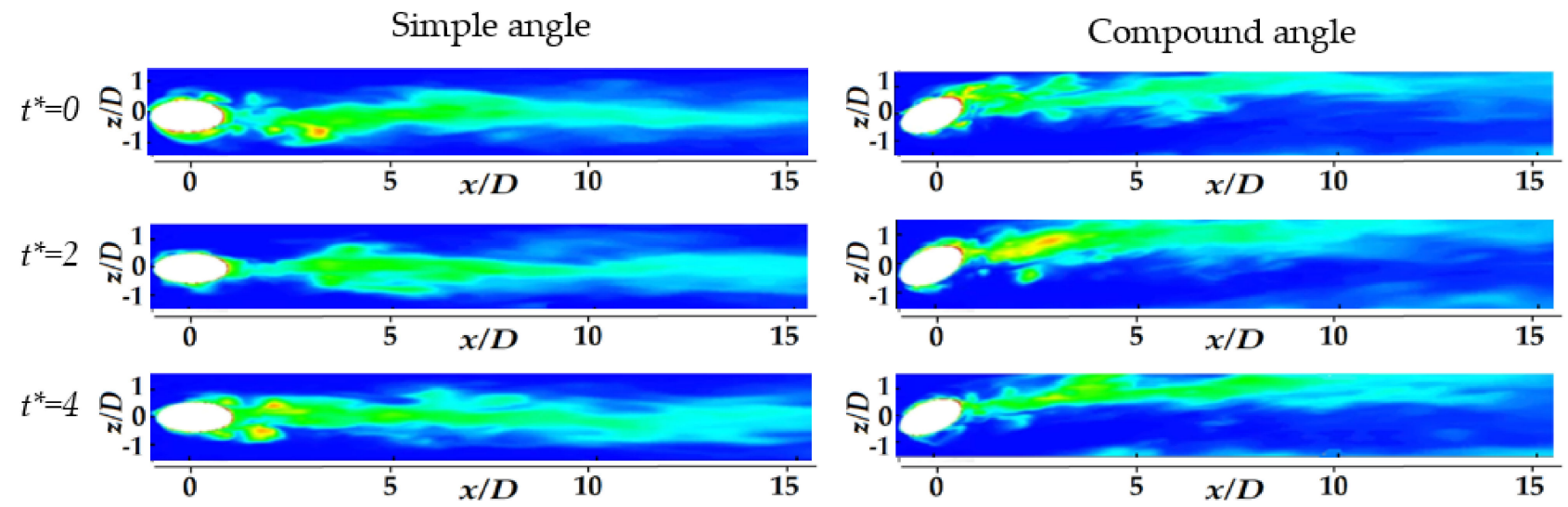

(a)

Figure 13. Cont. 

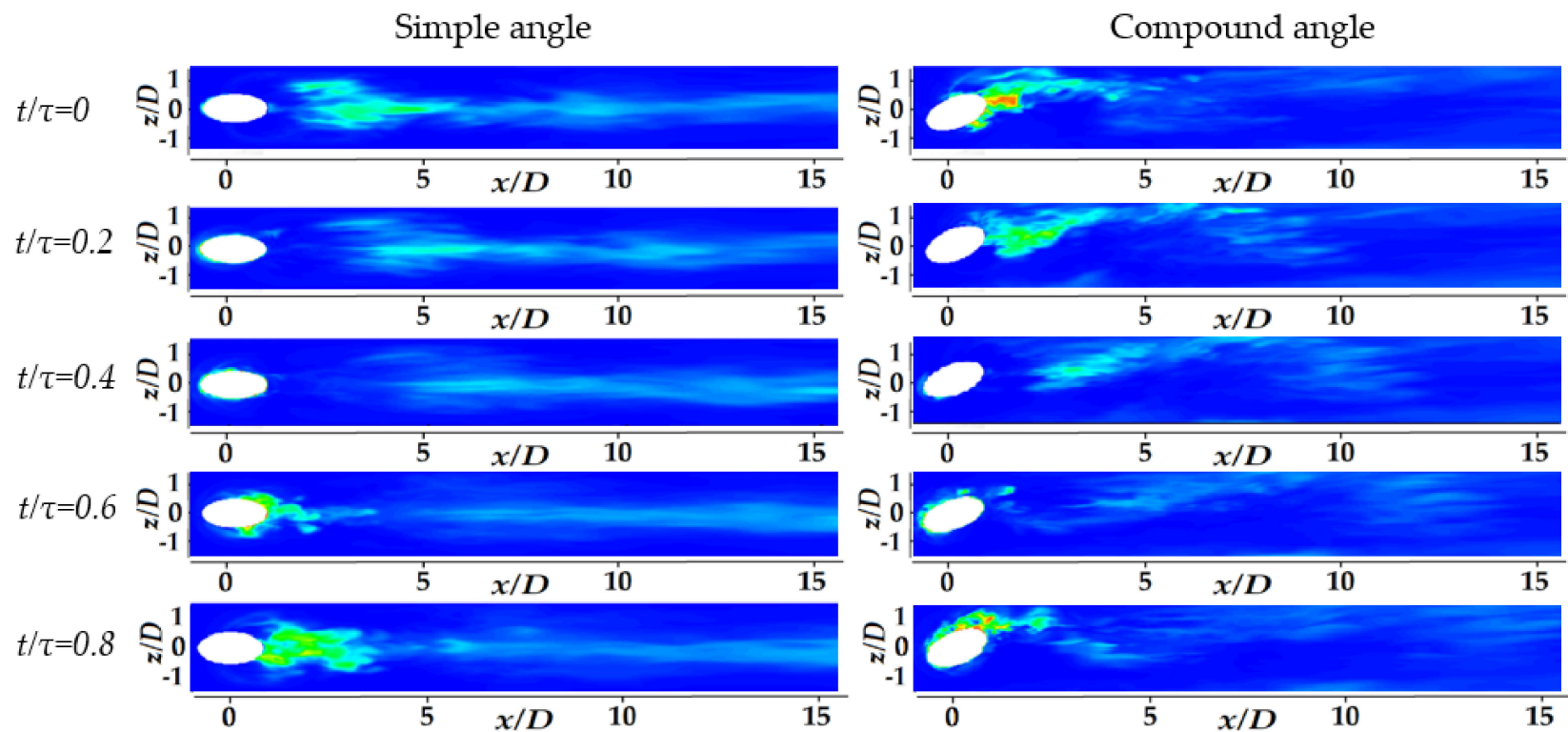

(b)

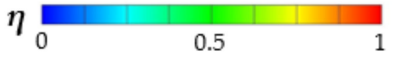

Figure 13. Instantaneous adiabatic film cooling effectiveness distributions for the simple angle and the orientation angle of $30^{\circ}$. (a) For the steady state $(0 \mathrm{~Hz})$; (b) $36 \mathrm{~Hz}$ pulsation.

\section{Conclusions}

CFD simulations for the film cooling from the cylindrical hole having the orientation angles of $0^{\circ}$ and $30^{\circ}$ on a flat plate having a $35^{\circ}$ inclined injection angle under $36 \mathrm{~Hz}$ flow pulsation at time-averaged blowing ratio of 0.5 were conducted by LES. The LES results were verified using experimental data from Jung [17] and compared to the RANS results to analyze whether LES improves the film cooling prediction for the compound angle under unsteady flow condition compared to RANS. When the pulsation was simultaneously applied in the main and coolant inlets, the spanwise-averaged film cooling effectiveness decreased for both LES and RANS, similar to that in the experimental data. LES results only exhibited small deviations from the experimental data, whereas RANS drastically overpredicted $\eta$ for the orientation angles of $0^{\circ}$ and $30^{\circ}$, especially for the $36 \mathrm{~Hz}$ flow pulsation. Moreover, the local distributions of the spanwise film cooling effectiveness in the spanwise direction predicted by RANS did not well match the experimental data, whereas LES predicted the distributions of the spanwise effectiveness with an acceptable accuracy. The LES contours of the film cooling effectiveness on the wall showed that the spread of injectant in the spanwise direction on the wall was larger than that in the RANS contours, and the coolant spreading in the LES contours was smaller than that in the experimental contours. In the dimensionless temperature contours on streamwisenormal planes, the coolant shape predicted by LES was more similar to the contours of the experimental data than that predicted by RANS. Especially for the $36 \mathrm{~Hz}$ flow pulsation, the coolant shape predicted by RANS was more different from the coolant shape in the contours of experimental data than that predicted by LES. In the phase-averaged dimensionless temperature contours, the LES results reflected the characteristics of the injectant concentration distributions at each phase in the experimental data better than the RANS results. Additionally, in the instantaneous dimensionless temperature contours on the spanwise-normal plane, the coolant jet lift off was clearly observed in the LES results, while it was not clearly observed in the RANS results, which increased the film cooling effectiveness predicted using RANS. 
Author Contributions: CFD simulation, S.-I.B.; analysis of the data, S.-I.B. and J.A.; writing, S.I.B. and J.A. supervision, J.A. All authors have read and agreed to the published version of the manuscript.

Funding: This work was supported by the UAV High Efficiency Turbine Research Center Program of Defense Acquisition Program Administration and Agency for Defense Development in South Korea.

Institutional Review Board Statement: Not applicable.

Informed Consent Statement: Not applicable.

Data Availability Statement: Not applicable.

Conflicts of Interest: The authors declare no conflict of interest.

\section{Nomenclature}

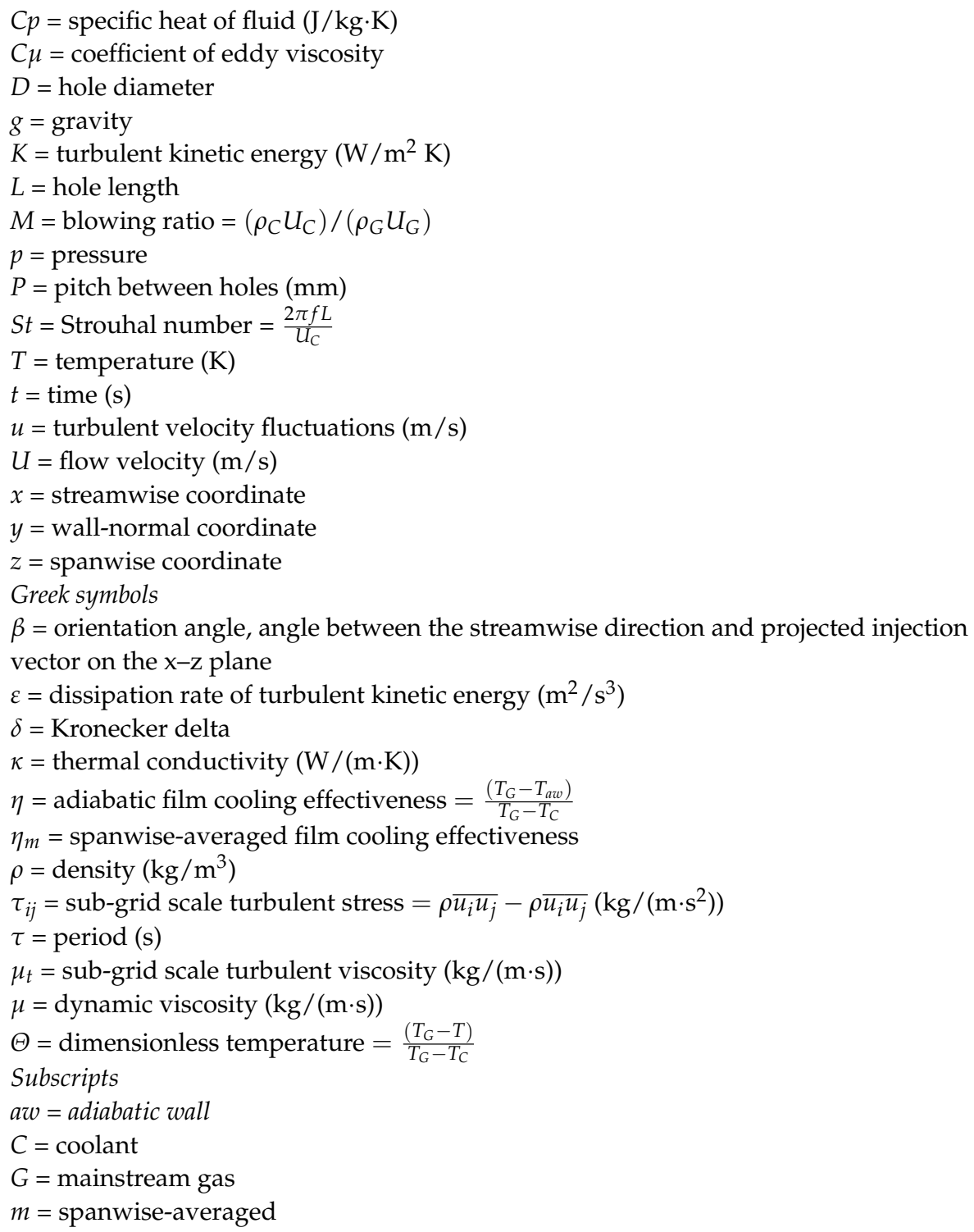

\section{References}

1. Moran, M.; Shapiro, H.; Boettner, D.; Bailey, M. Fundamentals of Engineering Thermodynamics, 8th ed.; Wiley: Hoboken, NJ, USA, 2014 ; p. 532.

2. Leedom, D.H.; Acharya, S. Large Eddy Simulations of Film Cooling Flow Fields From Cylindrical and Shaped Holes. In Proceedings of the ASME Turbo Expo 2008, Berlin, Germany, 9-13 June 2008; pp. 865-877. [CrossRef] 
3. Baek, S.; Ryu, J.; Ahn, J. Large Eddy Simulation of Film Cooling with Forward Expansion Hole: Comparative Study with LES and RANS Simulations. Energies 2021, 14, 2063. [CrossRef]

4. Bogard, D.G.; Thole, K. Gas Turbine Film Cooling. J. Propuls. Power 2006, 22, 249-270. [CrossRef]

5. Walters, D.K.; Leylek, J.H. Impact of Film-Cooling Jets on Turbine Aerodynamic Losses. J. Turbomach. 1999, 122, 537-545. [CrossRef]

6. Tyagi, M.; Acharya, S. Large Eddy Simulation of Film Cooling Flow From an Inclined Cylindrical Jet. J. Turbomach. 2003, 125, 734-742. [CrossRef]

7. Rozati, A.; Tafti, D.K. Large Eddy Simulation of Leading Edge Film Cooling-Part II: Heat Transfer and Effect of Blowing Ratio. In ASME Turbo Expo 2007; ASME: Montreal, QC, Canada, 2007.

8. Na, S.; Shih, T.I.-P. Increasing Adiabatic Film-Cooling Effectiveness by Using an Upstream Ramp. J. Heat Transf. 2006, $129,464-471$. [CrossRef]

9. Johnson, P.; Shyam, V.; Hah, C. Reynolds-Averaged Navier-Stokes Solutions to Flat Plate Film Cooling Scenarios. NASA/TM2011-217025. Available online: https:/ /ntrs.nasa.gov/api/citations/20110012464/downloads/20110012464.pdf (accessed on 1 October 2021).

10. Schmidt, D.L.; Sen, B.; Bogard, D.G. Film Cooling With Compound Angle Holes: Adiabatic Effectiveness. J. Turbomach. 1996, 118, 807-813. [CrossRef]

11. Ligrani, P.M.; Lee, J.S. Film Cooling from a Single Row of Compound Angle Holes at High Blowing Ratios. Int. J. Rotating Mach 1996, 2, 259-267. [CrossRef]

12. Lee, S.W.; Kim, Y.B.; Lee, J.S. Flow Characteristics and Aerodynamic Losses of Film-Cooling Jets with Compound Angle Orientations. J. Turbomach. 1997, 119, 310-319. [CrossRef]

13. Jung, I.S.; Lee, J.S. Effects of Orientation Angles on Film Cooling Over a Flat Plate: Boundary Layer Temperature Distributions and Adiabatic Film Cooling Effectiveness. J. Turbomach. 1999, 122, 153-160. [CrossRef]

14. Seo, H.J.; Lee, J.S.; Ligrani, P.M. The effect of injection hole length on film cooling with bulk flow pulsations. Int. J. Heat Mass Transf. 1998, 41, 3515-3528. [CrossRef]

15. Coulthard, S.M.; Volino, R.J.; Flack, K.A. Effect of Jet Pulsing on Film Cooling-Part I: Effectiveness and Flow-Field Temperature Results. J. Turbomach. 2006, 129, 232-246. [CrossRef]

16. Nikitopoulos, D.E.; Acharya, S.; Oertling, J.; Muldoon, F.H. On Active Control of Film-Cooling Flows. In Proceedings of the ASME Turbo Expo, Barcelona, Spain, 8-11 May 2006.

17. Jung, I.S. Effects of Bulk Flow Pulsations on Film Cooling with Compound Angle Injection Holes. Ph.D. Thesis, Seoul National University, Seoul, Korea, 1998.

18. Farhadi-Azar, R.; Ramezanizadeh, M.; Taeibi-Rahni, M.; Salimi, M. Compound Triple Jets Film Cooling Improvements via Velocity and Density Ratios: Large Eddy Simulation. J. Fluids Eng. 2011, 133. [CrossRef]

19. Han, J.-C.; Dutta, S.; Ekkad, S. Gas Turbine Heat Transfer and Cooling Technology, 2nd ed.; CRC Press: Boca Raton, FL, USA, 2012. [CrossRef]

20. Cengel, Y.; Cimbala, J. Fluid Mechanics, 3rd ed.; McGrawHill: New York, NY, USA, 2014.

21. White, F. Fluid Mechanics, 8th ed.; McGraw-Hill: New York, NY, USA, 2015.

22. ANSYS Fluent Theory Guide Version 19. Available online: https://www.ansys.com/products/fluids/ansys-fluent (accessed on 1 October 2021).

23. Acharya, S.; Leedom, D.H. Large Eddy Simulations of Discrete Hole Film Cooling with Plenum Inflow Orientation Effects. J. Heat Transf. 2012, 135, 011010. [CrossRef]

24. Pointwise Version 18. Available online: http://www.pointwise.com/ (accessed on 10 October 2021).

25. Baek, S.I.; Yavuzkurt, S. Effects of Flow Oscillations in the Mainstream on Film Cooling. Inventions 2018, 3, 73. [CrossRef]

26. Renze, P.; Schröder, W.; Meinke, M. Large-eddy Simulation of Film Cooling Flows with Variable Density Jets. Flow Turbul. Combust. 2007, 80, 119-132. [CrossRef]

27. Iourokina, I.; Lele, S. Towards large eddy simulation of film cooling flows on a model turbine blade leading edge. In Proceedings of the 43rd AIAA Aerospace Sciences Meeting and Exhibit, Reno, NV, USA, 10-13 January 2005.

28. Sakai, E.; Takahashi, T.; Watanabe, H. Large-eddy simulation of an inclined round jet issuing into a crossflow. Int. J. Heat Mass Transf. 2014, 69, 300-311. [CrossRef]

29. Zamiri, A.; You, S.J.; Chung, J.T. Large Eddy Simulation in the Optimization of Laidback Fan-Shaped Hole Geometry to Enhance Film-Cooling Performance. Int. J. Heat Mass Transf. 2020, 158, 120014. [CrossRef]

30. Thole, K.; Knost, D.G. Heat transfer and film-cooling for the endwall of a first stage turbine vane. Int. J. Heat Mass Transf. 2005, 48, 5255-5269. [CrossRef] 